\title{
Teaching College Algebra Using Web-Based, Project-Based and Peer-Led-Team Learnings
}

\author{
Anna Harris' ${ }^{1}$, Stephen Harris ${ }^{2}$, Sha'Nee Hulsey ${ }^{1}$, Tashombia Lindsey ${ }^{1}$ \\ ${ }^{1}$ Department of Mathematics and Computer Science, University of Arkansas at Pine Bluff, AR, USA \\ ${ }^{2}$ National Center for Toxicology Research/FDA, Jefferson, AR, USA \\ Email: harrisa@uapb.edu
}

How to cite this paper: Harris, A., Harris, S., Hulsey, S., \& Lindsey, T. (2020). Teaching College Algebra Using Web-Based, Project-Based and Peer-Led-Team Learnings. Creative Education, 11, 898-912. https://doi.org/10.4236/ce.2020.116065

Received: February 3, 2020

Accepted: June 27, 2020

Published: June 30, 2020

Copyright (c) 2020 by author(s) and Scientific Research Publishing Inc. This work is licensed under the Creative Commons Attribution International License (CC BY 4.0).

http://creativecommons.org/licenses/by/4.0/

\begin{abstract}
The University of Arkansas at Pine Bluff (UAPB) is the second oldest historically black land-grant institution in the state of Arkansas and has been producing well-qualified STEM scholars. However, STEM students at UAPB are affected by Mathematics classes, especially College Algebra. The purpose of this article is to share how the Department of Mathematics and Computer Science (MCS) increased the passing rates of College Algebra courses. MCS utilized three evidence-based (EB) instructional methods (WebAssign, Peer-Led-Team-Learning and Julia computer programing) and created a Co-Requisition College Algebra course to improve the passing rates of College Algebra courses. In addition, Math faculty received a 2-day faculty development training on EB instructional methods to properly and efficiently implement EB instructional methods. Through these activities the passing rates of College Algebra courses have improved. In addition, students who are enrolled in EB instructional College Algebra classes showed positive attitudes toward learning College Algebra according their survey results.
\end{abstract}

\section{Keywords}

Evidence-Based Learning, Active Learning, College Algebra, Web Assign, Peer-Led-Team-Learning (PLTL), Julia Computer Language

\section{Introduction}

There is rising concern about America's ability to maintain its competitive position in the global economy due to lack of graduates with training and expertise in Science, Technology, Engineering and Mathematics (STEM) fields (2012), and one of the primary reasons students switch or drop out of 
STEM disciplines is Mathematics instruction (Chen, 2013). Furthermore, according to a 2013 report by the United States Census Bureau, minority STEM workforce is well below their expected percentage in the total STEM workforce (Landivar, 2013). Studies also show that women, Blacks, and Hispanics are less likely to stay in STEM fields during college than male and non-minority students (Aud, Fox, \& Kewal Ramani, 2010; National Science Board, 2007).

The University of Arkansas at Pine Bluff (UAPB) is the second oldest historically black land-grant institution in the state of Arkansas. UAPB has been working very hard to produce well-qualified STEM scholars and increase minority STEM workforce. However, STEM students at UAPB are affected by Mathematics classes, especially College Algebra. College Algebra is one of major bottleneck courses for many STEM students at UAPB, especially incoming first-generation minority STEM students.

One of the main problems having low passing rates in College Algebra courses at UAPB is that we mainly utilize lecture-based instructional methods. The problem of lecture-based learning is a one-way communication, which treats students as passive participants who are to take notes while sitting quietly and who may ask questions only if time permits (Yuan, Williams, Yin, Fang, \& Pang, 2011). Research has shown that this rigid learning method is not helpful for most students in acquiring new knowledge (Hake, 1998; Benford, Brown, \& Cocking, 2000).

There have been numerous studies show that active-learning and other evidence-based instructions improve students' learning outcomes (Laursen, Hassi, Kogan, \& Weston, 2014; Ambrose, Bridges, DiPietro, Lovett, \& Norman, 2010; Prince \& Felder, 2007) and research also has shown that evidence-based learning methods in college mathematics may improve retention rates of STEM disciplines and attract more students to be in STEM fields, including minority students (Ellis, Rasemussen, \& Duncan, 2013; Watkins \& Mazur, 2013; Kogan \& Laursen, 2014). We implement three evidence based (EB) instructional methods to overcome our problems in College Algebra courses. Three EB instructional methods that we utilized are web-based learning (WBL), project-based learning (PBL), and peer-led-team learning (PLTL).

WBL is chosen because students are familiar with cloud service programs and online learning technology and also WBL research studies show positive effects on learning in general (Markham \& Lenz, 2002; Hwang \& Chang, 2011; Mayer, 2009; Yu, She, \& Lee, 2010). The three most popular WBL tools that are utilized at UAPB are Web Assign by Cengage, Connect Math by McGraw-Hill, and My MathLab by Pearson. These three online tools all have very good user-friendly resources for students and instructors. However, we chose WebAssign as our WBL tool because of their price and service. Our students only need to purchase one WebAssign code for all three algebra courses: Elementary Algebra, Intermediate Algebra and College Algebra. Since many of our students start with an 
Elementary Algebra class, WebAssign is the most cost-effective choice for our students.

PBL is implemented because PBL helps students form a positive attitude toward STEM disciplines (Midouser \& Betzer, 2007; Catherine \& Berry, 2008; Osborne, Simon, \& Collins, 2003) and efficiently integrate and apply STEM knowledge to real world problems (Tseng, Chang, Lou, \& Chen, 2013; George, 2003). PBL is an inquiry-based instruction that consists of a learner-centered environment that focuses on students' use of disciplinary concepts, tools, experiences, and technologies to answer questions and solve real-world problems (Krajcik \& Blumenfeld, 2006; Markham, Larmer, \& Ravitz, 2003). Since there are numerous research articles showing how computer coding enhances learning mathematics (Chen, 2016; Rabinovich, 2019), our PBL is focused in writing computer programs to solve mathematics problems. One of reasons why computer coding helps students to learn mathematics is that coding helps students to break a problem into small pieces and then reassemble the problem with step-by-step coding to solve the problem. These processes make students think about the problem deeply and logically instead of mimicking and memorizing steps (Tarr, 2019).

PLTL was originally designed and implemented for General Chemistry at the City College of New York (Woodward, Gosser, \& Weiner, 1993; Gosser, Roth, Gafney, Kampmeier, Strozak, Varma-Nelson, Stanley, \& Weiner, 1996). PLTL has also been implemented in undergraduate mathematics and other STEM courses and showed positive impact on students' learning outcomes and a drastic reduction in the failure rate for underrepresented minority students (Reisel, Jablonski, Munson, \& Hosseini, 2014; Merkel \& Branial, 2015; Snyder, Sloane, Dunk, \& Wiles, 2016). We closely follow their models to enhance our students' learning experience.

Although many studies show active/evidence-based methods are better learning tools than a traditional lecture, many instructors mainly utilize lecture-based instructional methods. The main barriers for instructors in embracing new techniques include the time required to find or create suitable active/evidence-based teaching materials and the lack of trainings on how to effectively implement supporting materials in their classroom (Gosser, Gracolice, Kampmeier, Roth, Strozak, \& Varma-Nelson, 2001; Lee, Blackwell, Drake, \& Moran, 2014; Reisel, Jablonski, Munson, \& Hosseini, 2014). Active/evidence-based learning methods cannot be successfully implemented, however, without properly training instructors. We plan to properly train our instructors with EB instructional methods during the summer workshops.

\section{Implementation Activities}

We designed and implemented the following activities to properly adapt three EB instructional methods. The goals of this study are to increase students' passing rates in College Algebra courses and to enhance mathematics learning expe- 
rience. Dr. Harris, a lead researcher, mathematics instructors, PLTL leaders and students from four College Algebra and one Co-Requisite College Algebra classes participated in this study.

\section{Activity 1: Hire, Train, and Mentor PLTL leaders}

PLTL leaders were hired and trained according to two Peer-Led Team Learning books: A Guidebook (Gosser, Gracolice, Kampmeier, Roth, Strozak, \& Varma-Nelson, 2001), and A Handbook for Team Leaders (Roth, Goldstein, \& Mancus, 2001). Since choosing right PLTL leaders is very important part of this implementation, Dr. Harris and College Algebra instructors were solely responsible for hiring, training, and mentoring PLTL leaders.

PLTL leaders were required to attend a mandatory 2-days workshop to receive proper training. In addition, College Algebra instructors and PLTL leaders met once a week to discuss group attendance, participation, and any concerns or problems with their groups during the semester. One of PLTL leaders' major duties was contacting their PLTL participants via social media to remind them to come to the study session. PLTL leaders conducted three surveys to their PLTL group participants, first one in the beginning of the semester, second one during the midterm, and third one in the end of the semester to collect data of the PLTL participants' experience.

PLTL leader hiring criteria that we used:

- Took College Algebra and Trigonometry or Pre-Calculus and Calculus I and Calculus II and made at least a "B" or better in each class, to ensure PLTL leaders' content knowledge.

- Have a good and positive attitude toward evidence-based learning methods and willingness to incorporate new learning methods.

- Have a positive reputation and attitude.

- Work well with other students and have the willingness to help other students.

- Are responsible students and encourage other students to study hard and come to PLTL study sessions.

- Summarized duties of PLTL leaders:

- Create PLTL groups (usually 6 or less students per group) with their assigned faculty in their assigned faculty's classroom during the first week of the semester.

- Decide group names, where to meet, and when to meet (required to study at least 6 hours per week).

- Meet with their assigned faculty for weekly study materials and to carry out any instructions for the week.

- Create GroupMe for each PLTL group.

- Remind their PLTL groups to attend study sessions via a call and/or text.

- Encourage their PLTL groups to come to study sessions and fill out the Google form timesheet for each PLTL study session. Google form contains where they met, when they met, and how many hours they studied, who participated, and any comments/incidents. 
- Be a role model to their PLTL groups.

- Report to their assigned faculty if there are any incidents or concerns. Activity 2: Professional Workshop

Dr. Harris provided a 2-days in-house active learning instructional workshop to mathematics instructors and PLTL leaders. Dr. Harris participated in active learning instructional trainings previously through Arkansas Math Pathways and Complete College for America and has extensive EB instructions experiences.

We chose WebAssign since Cengage offered one WebAssign code that works for three Algebra courses (Elementary, Intermediate, and College Algebra courses). For example, when a student purchases a WebAssign code for their Elementary Algebra course then the code works for other two math courses following semesters. For our department WebAssign was the most cost-effective web-based learning tool.

We also liked WebAssign since WebAssign assignments enhanced students' learning experiences. Students were able to utilize built-in resources, such as practicing a different version of assignments before they attempted to do their problems, watching short videos about the homework problems, and asking questions to their instructor via WebAssign. More information about WebAssign can be found here: https://www.webassign.net/how it works/.

Through the workshop mathematics instructors obtained the following WebAssign tools:

1) to create a class in WebAssign;

2) to use premade WebAssign assignments or build WebAssign assignments;

3) to upload worksheets or paper assignments;

4) to assign self-assessment tests to students' accounts;

5) to access WebAssign premade lecture videos;

6) to set up a grade book and

7) to download premade PowerPoint lessons.

To utilize PLTL study session effectively and efficiently we first discussed problems regards to College Algebra courses then we created or found materials for PLTL sessions. For example, many students do not know how to factor. To address remediation problems, we decided to utilize the KutaSoftware website (https://www.kutasoftware.com/freeica.html) for various Elementary and Intermediate Algebra worksheets. We also installed arithmetic and algebra games to our iPads that purchased through NSF grant so students can learn basic algebra and arithmetic skills while playing games. We have a math lab which is equipped with math books, large tables and chairs, smartboard, and 30 iPads.

For PBL we chose Julia programming language to do the coding projects since Julia is a high-level, high-performance, and easy to use and learn computer language. Julia is also free and very math friendly. More information about Julia can be found here: https://julialang.org/.

Dr. Harris showed how to download Julia software to our computers since we 
need to show our students how to download Julia software to their computers. Mr. Stephen Harris, NCTR/FDA computer programmer, and Dr. Harris created basic Julia tutorials and Dr. Harris gave basic Julia lessons to mathematics instructors and PLTL leaders. The tutorials covered Julia notebook, plots, expressions, evaluations, function creation and execution, and using built-in Julia functions and libraries. The Julia workshop materials that we used can be found at Dr. Harris' github account

(https://github.com/annaleeharris/Enhance-Minority-STEM-Majors-Mathemati cs-Performance). These Julia projects are required assignments for EB instructional College Algebra classes.

The Project 1 was geared toward writing short Julia functions using College Algebra algebraic formulas. This Julia project was developed to help students to learn basic Julia function syntax and procedures. This project required students to utilize distance, circle, slope, midpoint, perpendicular, and parallel formulas and basic math concepts to solve given problems.

The Project 2 was created to apply College Algebra concepts to real world problems so students can see the importance of College Algebra and how their obtained new knowledge can better serve them. This project is a hands-on project that students need to research from a reputable car rating website to find:

\section{Julia Project}

Given two points as the endpoints of a diameter of a circle: $\left(x_{1}, y_{1}\right)$ and $\left(x_{2}, y_{2}\right)$, create Julia function(s) to do the following:

1) Find the center of the circle (equivalent to midpoint): $\left(\frac{x_{1}+x_{2}}{2}, \frac{y_{1}+y_{2}}{2}\right)$ where $h=\frac{x_{1}+x_{2}}{2}$ and $k=\frac{y_{1}+y_{2}}{2}$

2) Find the radius of the circle (use Pythagorean Theorem): $r^{2}=\left(y_{1}-y_{2}\right)^{2}+\left(x_{1}-x_{2}\right)^{2}$

3) Find a circle equation: $(x-h)^{2}+(y-k)^{2}=r^{2}$

4) Find the slope of the given diameter: $m=\frac{x_{1}-x_{2}}{y_{1}-y_{2}}$

5) Find the equation of the perpendicular bisector of the given diameter (hint: perpendicular means its slope is $\frac{-1}{m}$ ):

6) Find end points of the second diameter

$$
\left(y-y_{1}\right)=\frac{-1}{m}\left(x-x_{1}\right)
$$

\section{Answer to \#1 problem}

Insert the given two points, $\left(x_{1}, y_{1}\right)$ and $\left(x_{2}, y_{2}\right)$, as inputs for the function "find_center". (Note: $h=\frac{x_{1}+x_{2}}{2}$ and $k=\frac{y_{1}+y_{2}}{2}$ )

In [1]: \#Insert given two points, (x1, y1) and (x2, y2), as inputs for the function "find c enter"

\# Answer to \#1 question

function find_center $(\mathrm{x} 1, \mathrm{y} 1, \mathrm{x} 2, \mathrm{y} 2)$

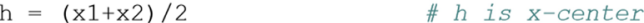

Out[1]: find_center (generic function with 1 method)

Project 1. College Algebra content specific Julia project. 


\section{Create functions to find the best car for money and gas mileage}

Choose a webstie such as Consumer Report, Edmund, Kelly Blue Book to choose top three recommended cars in a same catagory and make a recommendaiton using calculation results.

For example, according to the Consumer Reports the top three midsized cars are the following:

1. 2019 Subaru Legacy: purchase price: $\$ 22,852$, city mileage per galon: $26 \mathrm{mpg}$

2. 2019 Toyota Camry: purchase price: $\$ 22,639$, city mileage per galon: $32 \mathrm{mpg}$

3. 2019 Kia Optima: purchase price: $\$ 18,900$, city mileage per galon: $28 \mathrm{mpg}$

Create functions to calculate the best car for the money for the above three cars or choose any three cars of your choice in a same catagory. When you create any function use camel case which starts with a lowe case letter. For example, carTotalCost.

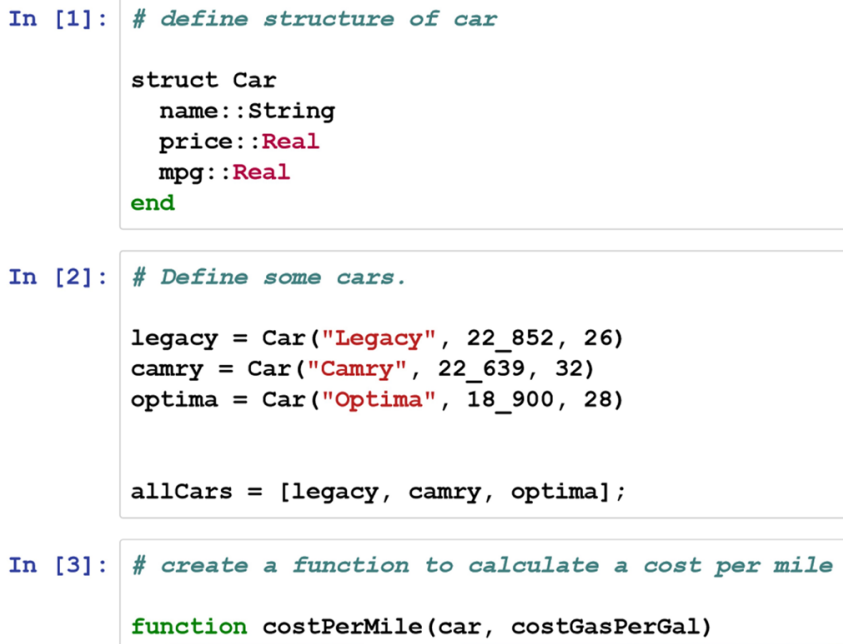

Project 2. College Algebra application Julia project.

1) three most recommended cars in a same car category;

2) their recommended car price and

3) local gas price per gallon.

After students find all three information, they have to determine which is the best car for the car price and gas millage. Students are required to write Julia functions to validate their answer.

\section{Activity 3: Weekly Meetings}

Dr. Harris, mathematics instructors and PLTL leaders met weekly to improve their implementations and share information. During these meetings we shared any problems, concerns, incidents, or successful implementation stories. PLTL leaders reported their PLTL study session attendance and discussed worksheets that they have completed. Monthly surveys regarding PLTL study session and PLTL leaders' opinions were collected using a Google Form.

\section{Results and Discussions}

College Algebra students overall liked EB instructions and the survey results showed positive feedback (see Google survey results in the Figure 1 and Figure 2; we used a linear scale: 1 , strongly disagree; 5 , strongly agree). The survey was given three times during the semester and College Algebra students responded 


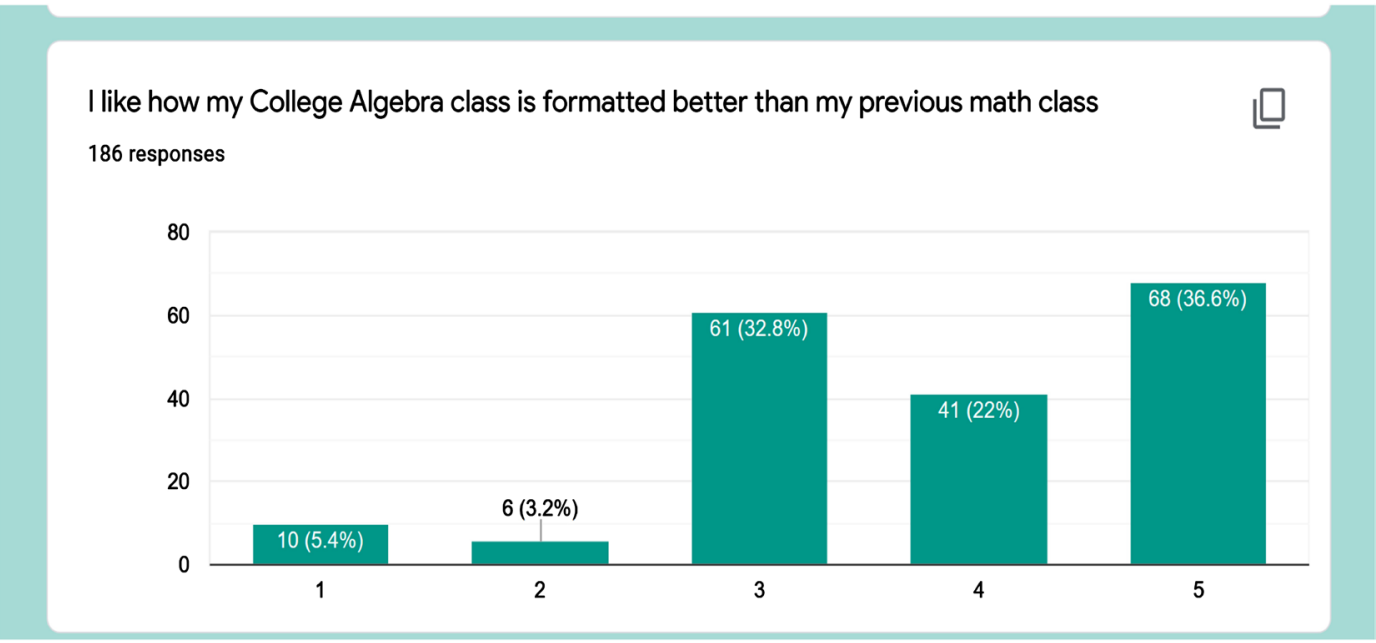

Figure 1. College Algebra active learning instructions overall survey results.

I like how my Co-Req College Algebra class is formatted better than my previous math class 12 responses

6

4

2

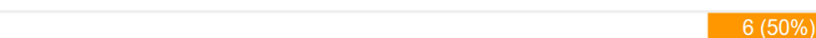

0

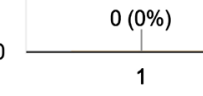

$0(0 \%)$

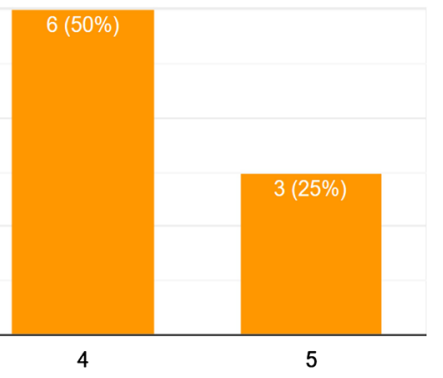

Figure 2. Co-Requisite College Algebra active learning instruction overall survey results.

185 responses and Co-Requisite College Algebra students gave 12 responses. Since this semester is the first time offering a Co-Requisite College Algebra class, the class was small. A few sample questions and responses are given below.

We utilized Cengage WebAssign as our web-based learning tool and created departmental standardized assignments in WebAssign; so, every College Algebra instructor will have the same resources. However, we ran into some problems since some students could/would not purchase the WebAssign code. WebAssign was a great tool for students who purchased an access code since it has a step-by-step guided solution, similar practice problems, videos, multiple-try-to-solve given problems, and a self-assessment tool. Students who could/would not purchase an access code were not able to fully utilize WebAssign tools to enhance their learning. For these students, instructors uploaded a printed copy of WebAssign homework assignments to Blackboard; so, they could turn in their work on paper.

The Google survey results reflect how students think about the WebAssign. 
Students who did not purchase WebAssign code usually gave a " 3 " for being neutral or no opinion (see the Figure 3 and Figure 4; we used a linear scale: 1, strongly disagree; 5 , strongly agree).

We hired, trained and mentored PLTL leaders. PLTL leaders did a wonderful job helping students and worked as coaches to inspire their peers. They used social media to contact their group members to come to PLTL study sessions. The Google survey results showed College Algebra students liked their PLTL leaders and PLTL study sessions (see the Figures 5-7; we used a linear scale: 1, strongly disagree; 5 , strongly agree).

We felt that having a 2-days workshop was efficient for learning WebAssign and were able to efficiently and effectively use WebAssign for our classes. However, utilizing Julia in class with students was harder than we anticipated. The Julia survey results showed mixed feedback (see the Figure 8 and Figure 9) STEM students wanted to use more Julia in their classwork but non-STEM students were overwhelmed with Julia projects. Fortunately, computer science major PLTL leaders were able to help students with Julia projects and they also

I like web-based learning (WebAssign) in my College Algebra class

186 responses

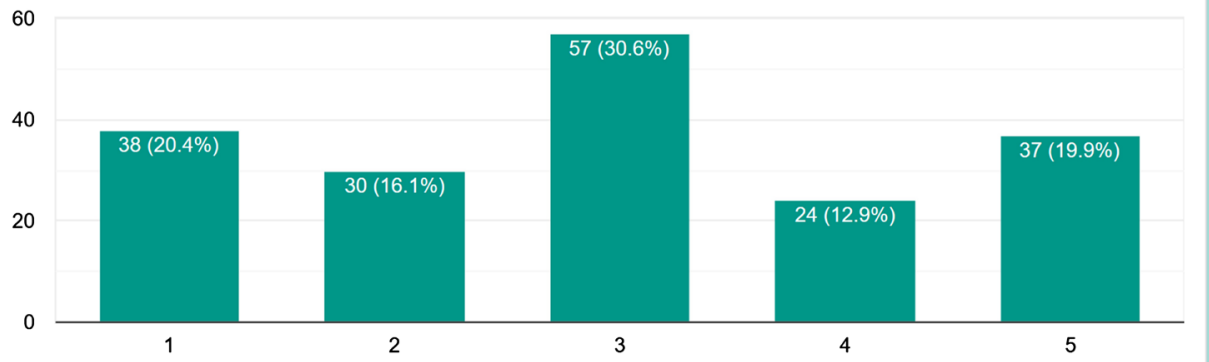

Figure 3. College Algebra class WebAssign survey results.

I like a web-based learning (WebAssign) in my Co-Req College Algebra class

12 responses

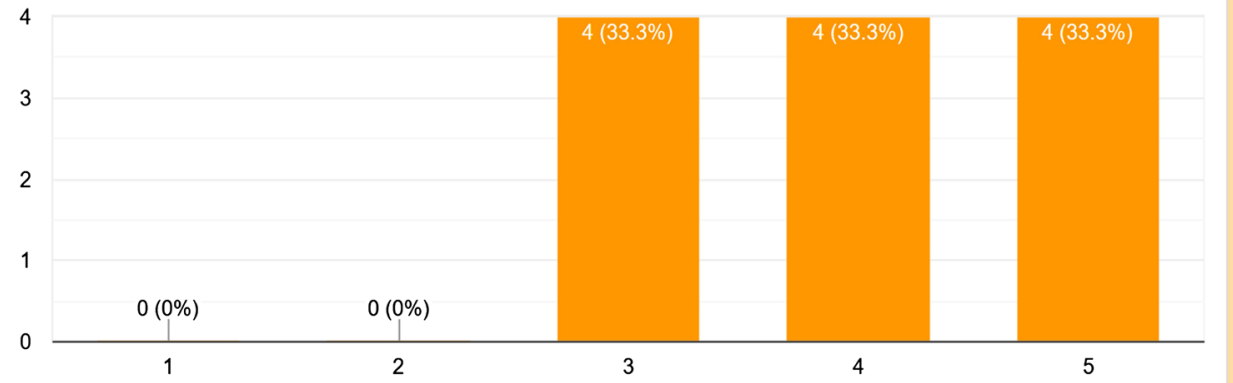

Figure 4. Co-Requisite College Algebra class WebAssign survey results. 
I like Peer-Led-Team-Learning (PLTL) workshop in my College Algebra class

186 responses

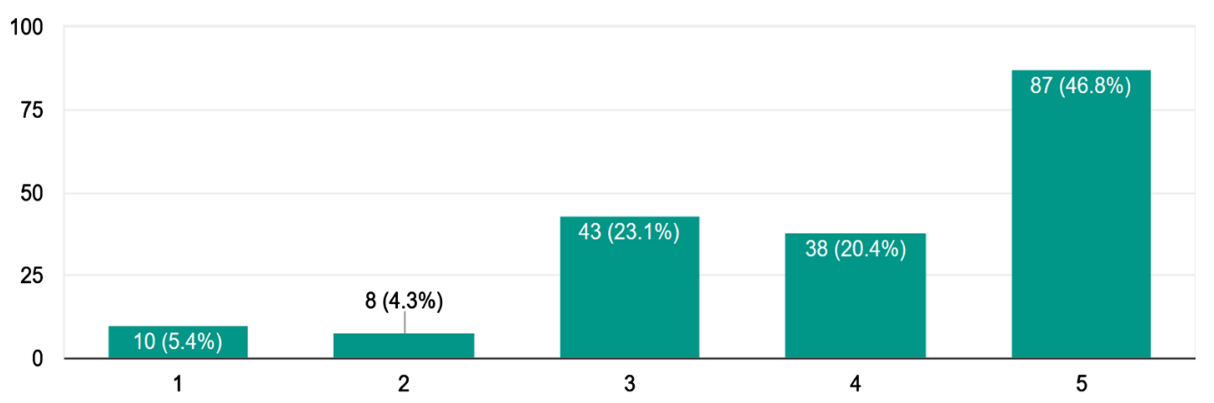

Figure 5. College Algebra class PLTL study session survey results.

I like my PLTL leader in my College Algebra class

186 responses

150

100

50

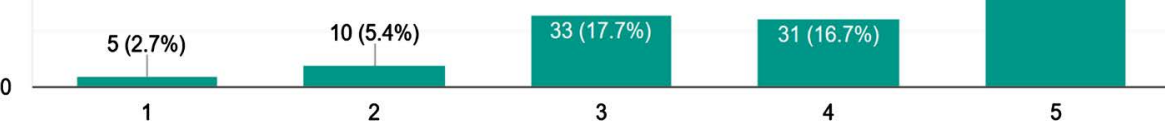

Figure 6. College Algebra class PLTL leader survey results.

PLTL workshop helped me to learn math better

186 responses

100

75

50

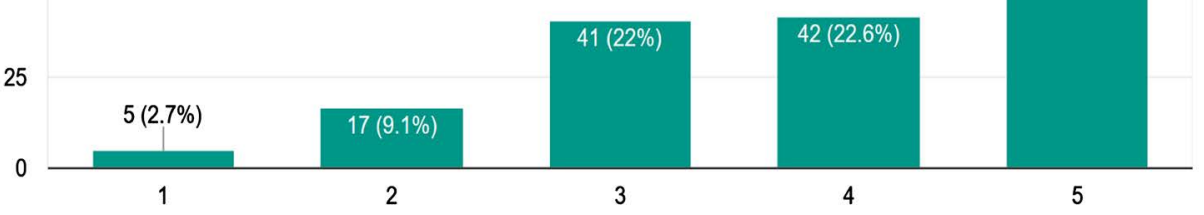

1

3

Figure 7. College Algebra class PLTL study session helped learning math survey results. 
I like Julia coding (project-based learning) in my Co-Req College Algebra class

12 responses

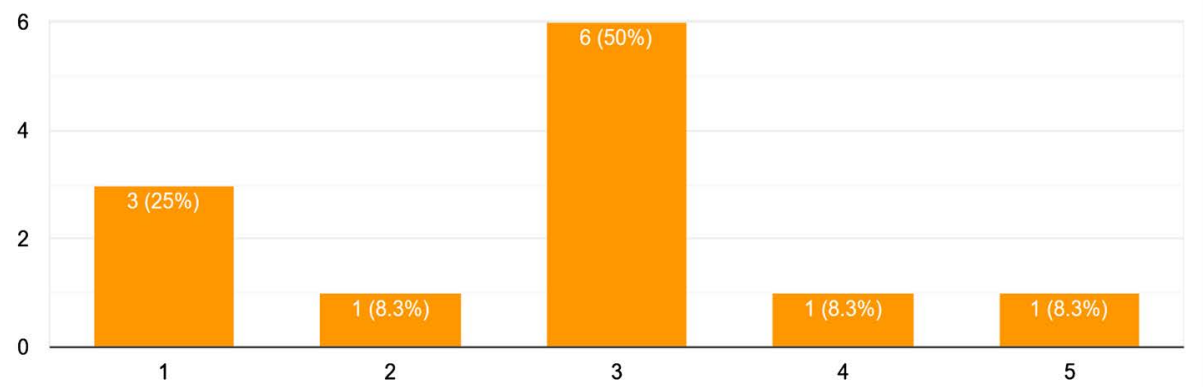

Figure 8. Co-Requisite College Algebra Julia coding survey results (1, strongly disagree and 5, strongly agree).

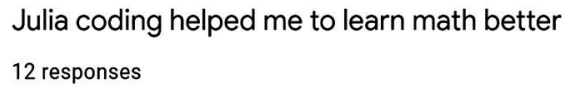

6

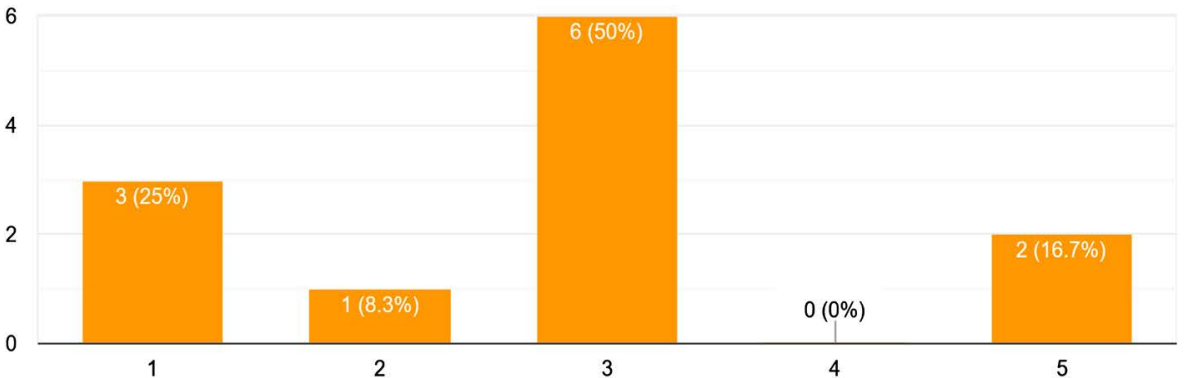

Figure 9. Co-Requisite College Algebra Julia coding and learning math survey results (1, strongly disagree and 5 , strongly agree).

came to our classroom to help our students.

Two math faculty piloted two College Algebra courses: one EB instructional method and one traditional method. They gave the exact same assignments, chapter exams, and the final exam to both of their classes and used the same percentages for each category of their gradebook. Each of four College Algebra classes had between 25 to 30 students and one Co-Requisite College Algebra class had 7 students. The difference between EB and traditional classes was that in the EB class, students had an option to attend PLTL study sessions and students were encouraged to use a Julia notebook instead of a calculator. The results showed that students in the EB instructional classes performed better than students in the traditional classes. Their p-value shows that these two different instructional methods have a statistically significant difference (see the Table 1). The Co-Requisite College Algebra course was implemented in the EB 
Table 1. College algebra and co-requisite college algebra classes' passing rates.

\begin{tabular}{cccc}
\hline Instructor & $\begin{array}{c}\text { Active Learning } \\
\text { Method Passing Rate }\end{array}$ & $\begin{array}{c}\text { Traditional } \\
\text { Method Passing Rate }\end{array}$ & P-Value \\
\hline Faculty 1 & $58.33 \%$ & $25.00 \%$ & 0.0001 \\
Faculty 2 & $66.67 \%$ & $58.33 \%$ & 0.0359 \\
Faculty 3 & $100.00 \%$ & & \\
\hline
\end{tabular}

method only and had an $100 \%$ passing rate. Co-Requisite College Algebra students had the same College Algebra WebAssign assignments, chapter exams, and final exam as regular College Algebra classes.

\section{Conclusion}

Active learning instructions impacted students' learning in positive ways and increased the passing rates of College Algebra courses having same College Algebra assignments and exams improved fairness and integrity of the course. Active learning instructional workshop helped instructors to be better prepared to teach their courses and improved their self-esteem. However, there were some problems that we need to address, and we plan to revise our implementation activities in our future studies. We plan to carry out more active learning implementations to fully understand the effects of the active learning instructions and share the updates in a near future.

Here are the listed problems with our EB implementations and proposed solutions to the listed problems:

WebAssign: We utilized Cengage WebAssign as their cyber/web-based learning tool and created departmental standardized assignments in WebAssign so every College Algebra instructor will have the same resources. WebAssign was a great tool for students who purchased an access code since it has a step-by-step guided solution, similar practice problems, videos, multiple-try-to-solve given problems, and a self-assessment tool. Students who could/would not purchase an access code were not able to fully utilize WebAssign tools to enhance their learning. For these students, instructors uploaded a printed copy of WebAssign homework assignments to Blackboard; so, they could turn in their work on paper.

Proposed Solution: We addressed the issue of students' unable to purchase a WebAssign access code to our administrators. We are seeking a permission to charge a fee of WebAssign access code to students' accounts which allowed students' financial aid to cover this fee like any other fees that are charged by UAPB.

Peer-led-team learning (PLTL): We hired, trained and mentored PLTL leaders. PLTL leaders did a wonderful job helping students and worked as coaches to inspire their peers. They used social media to contact their group members to come to PLTL workshops. They were required to come to a weekly meeting to share their progress and problems if there were any.

Problem: PLTL leaders who are Computer Science majors did not have any 
problem helping their peers with Julia coding but other PLTL leaders were not able to properly take this challenge.

Proposed Solutions: We plan to provide intensive Julia programing language training during the Summer workshop. PLTL leaders will also learn their duties and the activities that they need to carry out in the PLTL workshops 13.

Project-based learning (PBL): Julia project encouraged students to deeply think about the given math problems. If Julia project is implemented correctly, students can break the given mathematics problems into smaller pieces and write Julia functions to solve these mathematics problems.

Problem: The two-day professional workshop was a good start to know about Julia coding, but it was hardly enough time to master and implement in our College Algebra classes. College Algebra students, mathematics instructors, and most of PLTL leaders were not able to properly utilize Julia.

Proposed Solution: Dr. Harris plans to give a 10-days long summer workshop about Julia coding to mathematics instructors and PLTL leaders. In this workshop each participant will learn basics of Julia coding and also analyze Julia programs we used in College Algebra classes last semester. The goal of this workshop is that each workshop participant can comfortably use and write Julia coding for their given mathematics problems and is able to implement Julia projects properly.

\section{Funding}

This research was supported in part under National Science Foundation Historically Black Colleges and Universities Targeted Infusion Project Grant HRD-1818440.

\section{Conflicts of Interest}

The authors declare no conflicts of interest regarding the publication of this paper.

\section{References}

Ambrose, S., Bridges, M., DiPietro, M., Lovett, M. C., \& Norman, M. K. (2010). How Learning Works: Seven Research-Based Principles for Smart Teaching. San Francisco, CA: Jossey-Bass.

Aud, S., Fox, M., \& KewalRamani, A. (2010). Status and Trends in the Education of Racial and Ethnic Groups (NCES 2010-015). Washington, DC: US Government Printing Office.

Benford, J., Brown, A., \& Cocking, R. (2000). How People Learn: Brain, Mind, Experience and School. Washington, DC: National Academic Press.

Catherine, M., \& Berry, J. (2008). Learning Environment and Attitudes Associated with an Innovative Science Course Designed for Prospective Elementary Teachers. International Journal of Science and Mathematics Education, 6, 163-190. https://doi.org/10.1007/s10763-007-9070-2

Chen, H. (2016). Teaching Math with Computer Programming Can Help Narrow Achievement Gap.

https://edsource.org/2016/teaching-math-with-computer-programming-can-help-narr 
ow-achievement-gap/563371

Chen, X. (2013). STEM Attrition: College Students' Paths Into and Out of STEM Fields (NCES 2014-001). Washington, DC: National Center for Education Statistics, Institution of Education Science, U.S. Department of Education.

Ellis, J., Rasemussen, C., \& Duncan, K. (2013). Switcher and Persister Experience in Calculus I. In Sixteenth Annual Conference on Research in Undergraduate Mathematics Education, Denver, CO.

George, R. (2003). A Cross-Domain Analysis of Change in Students' Attitudes towards Science and Attitudes about the Untility of Science. International Journal of Science Education, 54, 571-689.

Gosser, D., Gracolice, M., Kampmeier, J., Roth, V., Strozak, V., \& Varma-Nelson, P. (2001). Peer-Led Team Learning: A Guidebook. Upper Saddle River, NJ: Prentice-Hall.

Gosser, D., Roth, V., Gafney, L., Kampmeier, J., Strozak, V., Varma-Nelson, P., Stanley, R., \& Weiner, R. (1996). Workshop Chemistry: Overcoming the Barriers to Student Success. The Chemistry Education, 1, 1-17. https://doi.org/10.1007/s00897960002a

Hake, R. R. (1998). Interactive-Engagement versus Traditional Methods: A Six-Thousand-Student Survey of Mechanics Test Data for Introductory Physics Courses. American Journal of Physics, 66, 64-74. https://doi.org/10.1119/1.18809

Hwang, G.-I., \& Chang, H.-F. (2011). A Formative Assessment-Based Mobil Learning Approach to Improving the Learning Attitudes and Achievements of Students. Computers and Education, 56, 1023-1031. https://doi.org/10.1016/j.compedu.2010.12.002

Kogan, M., \& Laursen, S. (2014). Assessing Long-Term Effects of Inquiry-Based Learning: A Case Study from College Mathematics. Innovative Higher Education, 39, 183-199. https://doi.org/10.1007/s10755-013-9269-9

Krajcik, J., \& Blumenfeld, P. (2006). 19. Project-Based Learning. In The Cambridge Handbook of the Learning Sciences (pp. 317-333). New York: Cambridge University Press. https://doi.org/10.1017/CBO9780511816833.020

Landivar, L. (2013). American Community Reports: Disparities in STEM Employment by Sex, Race, and Hispanic Origin. Washington, DC: The U.S. Census Bureau.

Laursen, S. L., Hassi, M.-L., Kogan, M., \& Weston, T. J. (2014). Benefits for Women and Men of Inquiry-Based Learning in College Mathematics: A Multi-Institutional Study. Journal for Research in Mathematics Education, 45, 406-418. https://doi.org/10.5951/jresematheduc.45.4.0406

Lee, J., Blackwell, S., Drake, J., \& Moran, K. (2014). Taking a Leap of Faith: Redefining Teaching and Learning in Higher Education through Project-Based Learning. Interdisciplinary Journal of Problem-Based Learning, 8, No. 2. https://doi.org/10.7771/1541-5015.1426

Markham, T., \& Lenz, B. (2002). Ready for the World. Educational Leadership, 59, 76-80.

Markham, T., Larmer, J., \& Ravitz, J. (2003). Project Based Learning Handbook: A Guide to Standards-Focused Project Based Learning (2nd ed.). Novato, CA: Buck Institute for Education.

Mayer, R. (2009). Multimedia Learning. New York: Cambridge University Press. https://doi.org/10.1017/CBO9780511811678

Merkel, J. C., \& Branial, A. (2015). Assessment of Peer-Led Team Learning in Calculus I: A Five-Year Study. Innovative Higher Education, 40, 415-428. https://doi.org/10.1007/s10755-015-9322-y

Midouser, D., \& Betzer, N. (2007). The Contribution of Project-Based-Learning to High Achievers' Acquisition of Technological Knowledge and Skills. International Journal of 
Technology and Design Education, 18, 59-77. https://doi.org/10.1007/s10798-006-9010-4

National Science Board (2007). A National Action Plan for Addressing the Critical Needs of the U.S. Science, Technology, Engineering, and Mathematics Education System. Arlington, VA: National Science Foundation.

Osborne, J., Simon, S., \& Collins, S. (2003). Attitudes towards Science: A Review of the Literature and Its Implications. International Journal of Science Education, 25, 1049-1079. https://doi.org/10.1080/0950069032000032199

Prince, M., \& Felder, R. (2007). The Many Facets of Inductive Teaching and Learning. Journal of College Science Teaching, 36, 14-20.

Rabinovich, A. (2019). Coding Is the New Math. Rabinovich, 2015.

Reisel, J., Jablonski, M., Munson, E., \& Hosseini, H. (2014). Peer-Led Team Learning in Mathematics Courses for Freshmen Engineering and Computer Science Students. Journal of STEM Education, 15, 7-15.

Roth, V., Goldstein, E., \& Mancus, G. (2001). Peer-Led Team Learning: A Handbook for Team Leaders. Upper Saddle River, NJ: Prentice-Hall, Inc.

Snyder, J. J., Sloane, J. D., Dunk, R. D. P., \& Wiles, J. R. (2016). Peer-Led Team Learning Helps Minority Students Succeed. PLoS Biology, 14, e1002398.

https://doi.org/10.1371/journal.pbio.1002398

Tarr, D. (2019). Coding Helps Students Learn Math. https://www.mvcode.com/articles/coding-helps-students-with-math

The President's Council of Advsiors on Science and Technology (2012). Report to the President. Engage to Excel: Producing One Million Additional College Graduates with Degree in Science, Technology, Engineering, and Mathematics.

http://www.whitehouse.gov/ostp/pcat

Tseng, K.-H., Chang, C.-C., Lou, S.-J., \& Chen, W.-P. (2013). Attitudes towards Science, Technology, Engineering and Mathematics (STEM) in a Project-Based Learning (PjBL) Environment. International Journal of Technology and Design Education, 23, 87-102. https://doi.org/10.1007/s10798-011-9160-x

Watkins, J., \& Mazur, E. (2013). Retaining Students in Science, Technology, Engineering and Mathematics (STEM) Majors. Journal of College Science Teaching, 42, 36-41.

Woodward, A., Gosser, D., \& Weiner, M. (1993). Problem Solving Workshops in General Chemistry. Journal of Chemistry Education, 70, 651-652.

https://doi.org/10.1021/ed070p651.1

Yu, W.-F., She, H.-C., \& Lee, Y.-M. (2010). The Effects of Web-Based/Non-Web-Based Problem-Solving Instruction and High/Low Achievement on Students' Problem-Solving Ability and Biology Achievement. Innovations in Education and Teaching International, 47, 187-199. https://doi.org/10.1080/14703291003718927

Yuan, H., Williams, B. A., Yin, L., Fang, J. B., \& Pang, D. (2011). Nursing Students' View on the Effectiveness of Problem-Based Learning. Nurse Education Today, 31, 577-581. https://doi.org/10.1016/j.nedt.2010.10.009 